\title{
Endovascular Treatment with Intravenous Thrombolysis versus Endovascular Treatment Alone for Acute Anterior Circulation Stroke : A Meta-Analysis of Observational Studies
}

\author{
Chul Ho Kim, M.D., Jin Pyeong Jeon, M.D.,, ${ }^{2,3}$ Sung-Eun Kim, M.D., ${ }^{4}$ Hyuk Jai Choi, M.D., ${ }^{2}$ Yong Jun Cho, M.D. ${ }^{2}$ \\ Department of Neurology, Hallym University College of Medicine, Chuncheon, Korea \\ Department of Neurosurgery, Hallym University College of Medicine, Chuncheon, Korea \\ Institute of New Frontier Research, ${ }^{3}$ Hallym University College of Medicine, Chuncheon, Korea \\ Department of Emergency Medicine, ${ }^{4}$ Seoul Emergency Operations Center, Seoul, Korea
}

Objective : The aim of this study was to determine outcome of ischemic stroke patients in the anterior circulation treated with endovascular treatment (EVT) with intravenous thrombolysis (IVT) versus EVT alone group.

Methods : A systemic literature review was performed using online database from January 2004 to January 2017. Primary outcomes were successful recanalization seen on finial angiography and good outcome at three months. Secondary outcomes were mortality and the development of symptomatic intracranial hemorrhage $(\mathrm{S}-\mathrm{ICH})$ after the procedure. A fixed effect model was used when heterogeneity was less than $50 \%$. Egger's regression test was used to assess publication bias.

Results : Five studies were included for final analysis. Between EVT with IVT and EVT alone group, successful recanalization (odds ratio $[O R] 1.467, p=0.216)$, good clinical outcome at three months (OR 1.199, $p=0.385)$, mortality (OR 0.776, $p=0.371)$, and S-ICH (OR $1.820, p=0.280$ ) did not differ significantly. Egger's regression intercept with $95 \%$ confidence interval (Cl) was $1.99(95 \% \mathrm{Cl}-2.91$ to $6.89)$ in successful recanalization and $-0.27(95 \% \mathrm{Cl}-6.35$ to 5.80$)$ in good clinical outcome, respectively.

Conclusion : The two treatment modalities, EVT with IVT and EVT alone, could be comparable in treating acute anterior circulation stroke. Studies to find specific beneficiary group for EVT alone, without primary IVT, are needed further.

Key Words : Thrombectomy · Stroke · Endovascular procedures $\cdot$ Mechanical thrombolysis.

\section{INTRODUCTION}

The superiority of endovascular treatment (EVT) than medical treatment including intravenous thrombolysis (IVT) using recombinant tissue plasminogen activator has been well documented for large arterial occlusion in anterior circula- tion $^{8)}$. Nevertheless, the beneficial effect of IVT on EVT outcome remains inconclusive. Most studies have focused on treatment outcome through comparative test between medical and EVT (with or without prior IVT). It has been reported that patients treated with IVT have better clinical outcomes than those without $\mathrm{IVT}^{7}$. However, some patients could not

- Received : May 16, 2017 •Revised : August 10, 2017 •Accepted : September 8, 2017

- Address for reprints : Jin Pyeong Jeon, M.D.

Department of Neurosurgery, Hallym University College of Medicine, 77 Sakju-ro, Chuncheon 24253, Korea

Tel : +82-33-240-5171, Fax : +82-33-240-9970, E-mail : jjs6553@daum.net

This is an Open Access article distributed under the terms of the Creative Commons Attribution Non-Commercial License (http://creativecommons.org/licenses/by-nc/4.0) which permits unrestricted non-commercial use, distribution, and reproduction in any medium, provided the original work is properly cited. 
undergo IVT with recombinant tissue plasminogen activator due to ineligible clinical circumstances (oral anticoagulant, malignancy, surgery, and bleeding, etc.) within 4.5 hours of ischemic symptoms onset. In addition, IVT alone may be less likely to be effective for patients with heavy clot burden ${ }^{13)}$. Moreover, EVT becomes more widely available to various physicians, radiologists, neurosurgeon, and neurologist. Accordingly, the rationale of EVT with IVT for all patients if they are eligible for IVT should be evaluated further in acute ischemic stroke in the era of mechanical thrombectomy. The aim of our study was to determine whether EVT with IVT might have better clinical and angiographic outcomes compared to EVT alone.

\section{MATERIALS AND METHODS}

\section{Literature search}

Medline bibliographic database including PubMed, Embase, and the Cochrane Central Register of Controlled trials in Cochrane Library published between January 2004 and January 2017 were searched using the following key words : "ischemic stroke", "endovascular therapy", "cerebral infarct", "intra-venous", "intra-arterial", "fibrinolysis" ") "thrombolysis", "thrombectomy", "bridging thrombolysis", "IV Tpa", "hemorrhage", "embolus", "eath", "peri-operative complications", and "mortality".

\section{Selection criteria and data abstraction}

This meta-analysis was performed according to Preferred Reporting Items for Systematic Reviews and Meta-Analyses (PRISMA) guidelines. Inclusion criteria for this study were : 1) studies that included patients presenting acute ischemic stroke in the anterior circulation; 2) participants of over 18 years; 3 ) endovascular treatments such as intra-arterial thrombolysis using tissue plasminogen activator or urokinase and mechanical thrombectomy with stent retrieval, Merci retriever, or suction devices; 4) endovascular procedures over 10 through common femoral artery were done; 5) clinical information on angiographic recanalization, outcome, mortality and complications could be extracted; 6) clear information on the use of EVT with IVT; and 7) prospective or retrospective case-controlled studies with quality score over 5 on Newcastle-Ottawa scale. Exclusion criteria were : 1) patients who did not show acute ischemic stroke; 2) incomplete data or unclear distinction between EVT with IVT and EVT alone group; 3) review article or case report; 4) outcomes regarding successful recanalization and clinical status at three months after the procedures could not be extracted; and 5) study not written in English ${ }^{9)}$.

Primary outcomes were successful recanalization seen on finial angiography and good outcome at three months. Secondary outcomes were mortality and the development of symptomatic intracranial hemorrhage (S-ICH) after the procedure. Subgroup analysis compared direct treatment outcomes between EVT with IVT and EVT alone for patients who were not contraindicated for IVT. Successful recanalization was defined as thrombolysis in cerebral ischemia $\geq 2 b$ or thrombolysis in myocardial infarction grade 2 or $3^{1)}$. Good clinical outcome was defined when 3 -month modified Rankin scale score was $\leq 2$. S-ICH was defined as any intracerebral hemorrhage concomitant with an increase of the $\mathrm{Na}$ tional Institutes of Health Stroke Scale score of at least 4 within 24 hours or resulting in death ${ }^{14)}$. Two authors (J.P.J. and C.H.K.) independently evaluated the eligibility of these studies and extracted data using a uniform standardized form. Disagreement between the two authors was resolved by discussion and consultation with a third author.

\section{Statistical analysis}

Cumulative incidence (event rate) and 95\% confidence interval (CI) were estimated from each study. Dichotomous variables are presented as odds ratio (OR) with a 95\% CI. Heterogeneity was evaluated by using $\mathrm{I}^{2}$ test. If $\mathrm{I}^{2}$ was less than $50 \%$, a fixed effect model was used ${ }^{18)}$. Publication bias was determined using Egger's test of the intercept and the rank correlation test of Begg and Mazumdar ${ }^{2,11)}$. Comprehensive metaanalysis (CMA) software (CMA v2.2.064, Biostat, Englewood, NJ, USA) was used for all analyses. Statistical significance was set at $p<0.05$.

\section{RESULTS}

\section{Study selection}

A flow chart of detailed processes used for the identification of relevant studies is shown in Fig. 1. After screening records and deciding eligibility, five articles were selected for analysis. 
Among them, four studies ${ }^{10,15,19,20)}$ compared treatment outcomes between EVT with IVT and EVT alone for patients who were ineligible for IVT. Detailed information of these studies are summarized in Table 1.

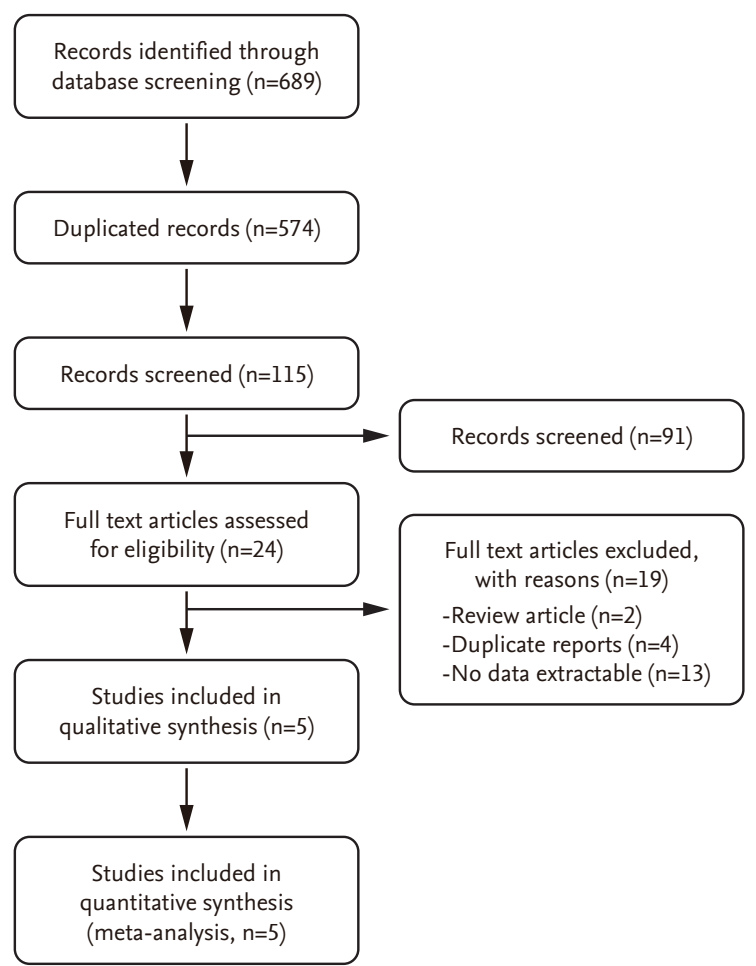

Fig. 1. Flow chart showing the process used for the identification of relevant studies.

\section{Comparison of treatment outcomes between EVT with IVT and EVT alone}

A total of five studies with 457 patients compared variables of successful recanalization, good clinical outcome at three months, mortality, and S-ICH. Of these studies, one ${ }^{19)}$ was excluded from the analysis of S-ICH because it did not provide any information for S-ICH. The number of successful recanalization was 221 (84.4\%) in EVT with IVT and 154 (79.0\%) in EVT alone group. Successful recanalization rate did not differ significantly according to the use of IVT (OR 1.467, 95\% CI $0.799-2.692, p=0.216$ ) (Fig. 2A). EVT with IVT tended to show better clinical outcome than EVT alone. However, the difference between the two was not statistically significant (OR 1.199, 95\% CI 0.796-1.805, $p=0.385$ ) (Fig. 2B). Mortality (OR $0.776,95 \%$ CI $0.445-1.353, p=0.371)$ and S-ICH (OR 1.820 , 95\% CI 0.614-5.393, $p=0.280)$ did not differ significantly either between the two groups (Fig. 2C and D).

\section{Publication bias}

In publication bias analysis for comparison of successful recanalization between EVT with IVT and EVT alone, Egger's regression test revealed an intercept of 1.99 (95\% CI -2.91 to $6.89, \mathrm{t}=1.29, \mathrm{df}=3$, two-tailed $p=0.29$ ). For rank correlation test, Kendall's tau was 0.1 with two-tailed $p$ value of 0.81 . Regarding good clinical outcome at three months, Egger's regression test revealed an intercept of -0.27 (95\% CI -6.35 to 5.80 , $\mathrm{t}=0.14, \mathrm{df}=3$, two-tailed $p=0.48$ ). For rank correlation test,

Table 1. Clinical data of studies included in this meta-analysis

\begin{tabular}{|c|c|c|c|c|c|c|c|c|c|c|}
\hline Study & $\begin{array}{l}\text { Center/ } \\
\text { design }\end{array}$ & Treatment & $\begin{array}{l}\text { Onset time } \\
\text { (hours) }\end{array}$ & $\begin{array}{l}\text { Total } \\
\text { No. }\end{array}$ & $\begin{array}{c}\text { Age } \\
\text { (years) }\end{array}$ & NIHSS & $\begin{array}{c}\text { Successful } \\
\text { recanalization }\end{array}$ & $\begin{array}{c}\text { Good } \\
\text { outcome }\end{array}$ & Mortality & S-ICH \\
\hline \multirow[t]{2}{*}{ Sallustio et al. $(2013)^{20)}$} & S/Retro & EVT with IVT & 4.5 & 16 & 64.5 & 19 & $16(100.0 \%)$ & $7(43.8 \%)$ & $2(12.5 \%)$ & $2(12.5 \%)$ \\
\hline & S/Retro & EVT alone & 6 & 30 & 68.2 & 18 & 27 (90.0\%) & $12(40.0 \%)$ & $10(33.3 \%)$ & $3(10.0 \%)$ \\
\hline \multirow[t]{2}{*}{ Guedin et al. $(2015)^{10)}$} & S/Retro & EVT with IVT & 4.5 & 28 & 69.2 & $18^{*}$ & $27(96.4 \%)$ & 19 (67.9\%) & $3(10.7 \%)$ & $2(7.1 \%)$ \\
\hline & S/Retro & EVT alone & 6 & 40 & 64.6 & $15^{*}$ & $29(72.5 \%)$ & $21(52.5 \%)$ & $7(17.5 \%)$ & $2(5.0 \%)$ \\
\hline \multirow[t]{2}{*}{ Leker et al. $(2015)^{15)}$} & S/Retro & EVT with IVT & 4.5 & 24 & $66.8^{*}$ & $19.2^{*}$ & $21(87.5 \%)$ & $10(41.7 \%)$ & $3(12.5 \%)$ & $2(8.3 \%)$ \\
\hline & S/Retro & EVT alone & 8 & 33 & $64.4^{*}$ & $19.1^{*}$ & $28(84.8 \%)$ & $17(51.5 \%)$ & $3(9.1 \%)$ & 0 \\
\hline \multirow{2}{*}{$\begin{array}{l}\text { Broeg-Morvay et al. } \\
(2016)^{3)}\end{array}$} & S/Retro & EVT with IVT & 4.5 & 156 & 73 & $15^{*}$ & $126(80.8 \%)$ & $71(45.5 \%)$ & $41(26.3 \%)$ & $7(4.5 \%)$ \\
\hline & S/Retro & EVT alone & 4.5 & 40 & 77 & $17^{*}$ & $35(87.5 \%)$ & $17(42.5 \%)$ & $8(20.0 \%)$ & $1(2.5 \%)$ \\
\hline \multirow[t]{2}{*}{ Rai et al. $(2017)^{19)}$} & S/Retro & EVT with IVT & 4.5 & 38 & 63 & $18^{*}$ & 31 (81.6\%) & 22 (57.9\%) & 4 (10.5\%) & NC \\
\hline & S/Retro & EVT alone & 4.5 & 52 & 69 & $16^{*}$ & 35 (67.3\%) & $26(50.0 \%)$ & $13(25.0 \%)$ & NC \\
\hline
\end{tabular}

*Indicates median value. NIHSS : National Institutes of Health Stroke Scale, S-ICH : symptomatic intracranial hemorrhage, S: single center, Retro : retrospective studies, EVT : endovascular treatment, IVT : intravenous thrombolysis, NC : no comment 


\begin{tabular}{|c|c|c|c|c|c|c|c|}
\hline \multirow[t]{2}{*}{ Study name } & \multicolumn{2}{|c|}{ Events/total } & \multicolumn{5}{|c|}{ Statistics for each study } \\
\hline & EVT+IVT & $\begin{array}{c}\text { EVT } \\
\text { alone }\end{array}$ & $\begin{array}{l}\text { Odds } \\
\text { ratio }\end{array}$ & $\begin{array}{c}\text { Lower } \\
\text { limit }\end{array}$ & $\begin{array}{l}\text { Upper } \\
\text { limit }\end{array}$ & Z-value & $p$-value \\
\hline Sallustio et al. $(2013)^{20)}$ & $16 / 16$ & $27 / 30$ & 4.200 & 0.204 & 86.529 & 0.930 & 0.353 \\
\hline Guedin et al. $(2015)^{10)}$ & $27 / 28$ & $29 / 40$ & 10.241 & 1.238 & 84.740 & 2.158 & 0.031 \\
\hline Leker et al. $(2015)^{15)}$ & $21 / 24$ & $28 / 33$ & 1.250 & 0.268 & 5.826 & 0.284 & 0.776 \\
\hline Broeg-Morvay et al. (2016)3) & $126 / 156$ & $35 / 40$ & 0.600 & 0.217 & 1.661 & -0.983 & 0.325 \\
\hline Rai et al. $(2017)^{19)}$ & $31 / 38$ & $35 / 52$ & 2.151 & 0.788 & 5.872 & 1.495 & 0.135 \\
\hline & & & 1.467 & 0.799 & 2.692 & 1.236 & 0.216 \\
\hline
\end{tabular}

Heterogeneity : $x^{2}=7.275 ; \mathrm{df}=4(p=0.122)$,
(A) Test for overall effect : $Z=1.236(p=0.216)$

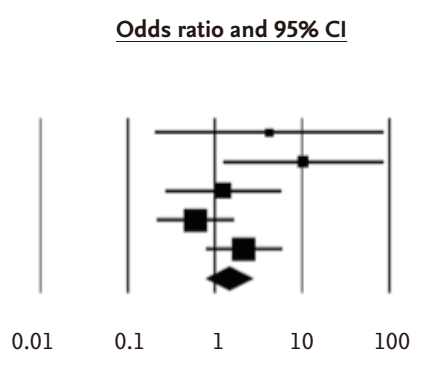

Favors EVT alone Favours EVT with IVT

\section{Study name}

Sallustio et al. $(2013)^{20)}$
Guedin et al. $(2015)^{10)}$
Leker et al. $(2015)^{15)}$
Broeg-Morvay et al. $(2016)^{3)}$
Rai et al. $(2017)^{19)}$

\section{Events/total}

$\begin{array}{ccc}\text { EVT+IVT } & \begin{array}{c}\text { EVT } \\ \text { alone }\end{array} & \begin{array}{c}\text { Odds } \\ \text { ratio }\end{array} \\ 7 / 16 & 12 / 30 & 1.167 \\ 19 / 28 & 21 / 40 & 1.910 \\ 10 / 24 & 17 / 33 & 0.672 \\ 71 / 156 & 17 / 40 & 1.130 \\ 22 / 38 & 26 / 52 & 1.375 \\ & & 1.199\end{array}$

$\begin{array}{llrr}\begin{array}{l}\text { Lower } \\ \text { limit }\end{array} & \begin{array}{c}\text { Upper } \\ \text { limit }\end{array} & \text { Z-value } & p \text {-value } \\ 0.342 & 3.985 & 0.246 & 0.806 \\ 0.698 & 5.299 & 1.259 & 0.208 \\ 0.233 & 1.941 & -0.734 & 0.463 \\ 0.560 & 2.279 & 0.342 & 0.733 \\ 0.592 & 3.194 & 0.741 & 0.459 \\ 0.796 & 1.805 & 0.869 & 0.385\end{array}$

Heterogeneity : $x^{2}=2.096, d f=4(p=0.718) ;\left.\right|^{2}=0.000 \%$

(B)

Test for overall effect : $Z=0.869(p=0.385)$ ns 0615
Statistics for each study

-value

0.806

0.463

0.733

0.385

\begin{tabular}{|c|c|c|c|c|c|c|c|}
\hline \multirow[t]{2}{*}{$\underline{\text { Study name }}$} & \multicolumn{2}{|c|}{ Events/total } & \multicolumn{5}{|c|}{ Statistics for each study } \\
\hline & $\mathrm{EVT}+\mathrm{IVT}$ & $\begin{array}{l}\text { EVT } \\
\text { alone }\end{array}$ & $\begin{array}{l}\text { Odds } \\
\text { ratio }\end{array}$ & $\begin{array}{l}\text { Lower } \\
\text { limit }\end{array}$ & $\begin{array}{l}\text { Upper } \\
\text { limit }\end{array}$ & Z-value & $p$-value \\
\hline Sallustio et al. $(2013)^{20)}$ & $2 / 16$ & $10 / 30$ & 0.286 & 0.054 & 1.510 & -1.475 & 0.140 \\
\hline Guedin et al. $(2015)^{10)}$ & $3 / 28$ & $7 / 40$ & 0.566 & 0.133 & 2.409 & -0.771 & 0.441 \\
\hline Leker et al. $(2015)^{15)}$ & $3 / 24$ & $3 / 33$ & 1.429 & 0.262 & 7.778 & 0.413 & 0.680 \\
\hline Broeg-Morvay et al. (2016) & $41 / 156$ & $8 / 40$ & 1.426 & 0.608 & 3.346 & 0.816 & 0.415 \\
\hline \multirow[t]{2}{*}{ Rai et al. $(2017)^{19)}$} & $4 / 38$ & $13 / 52$ & 0.353 & 0.105 & 1.185 & -1.685 & 0.092 \\
\hline & & & 0.776 & 0.445 & 1.353 & -0.894 & 0.371 \\
\hline \multicolumn{8}{|c|}{$\begin{array}{l}\text { Heterogeneity : } x^{2}=5.646 ; d f=4(p=0.227) ; l^{2}=29.149 \% \\
\text { Test for overall effect : } Z=-0.894(p=0.371)\end{array}$} \\
\hline \multirow[t]{2}{*}{ Study name } & \multicolumn{2}{|c|}{ Events/total } & \multicolumn{5}{|c|}{ Statistics for each study } \\
\hline & EVT+IVT & $\begin{array}{c}\text { EVT } \\
\text { alone }\end{array}$ & $\begin{array}{l}\text { Odds } \\
\text { ratio }\end{array}$ & $\begin{array}{l}\text { Lower } \\
\text { limit }\end{array}$ & $\begin{array}{l}\text { Upper } \\
\text { limit }\end{array}$ & Z-value & $p$-value \\
\hline Sallustio et al. $(2013)^{20)}$ & $2 / 16$ & $3 / 30$ & 1.286 & 0.192 & 8.164 & 0.259 & 0.796 \\
\hline Guedin et al. $(2015)^{10)}$ & $2 / 28$ & $2 / 40$ & 1.462 & 0.193 & 11.045 & 0.368 & 0.713 \\
\hline Leker et al. $(2015)^{15)}$ & $2 / 24$ & $0 / 33$ & 7.444 & 0.341 & 162.466 & 1.276 & 0.202 \\
\hline \multirow[t]{2}{*}{ Broeg-Morvay et al. (2016) } & $7 / 156$ & $1 / 40$ & 1.832 & 0.219 & 15.337 & 0.559 & 0.576 \\
\hline & & & 1.820 & 0.614 & 5.393 & 1.081 & 0.280 \\
\hline
\end{tabular}

Heterogeneity : $x^{2}=0.975, d f=3(p=0.807) ; l^{2}=0.000 \%$

(D) Test for overall effect: $Z=1.081(p=0.280)$
Odds ratio and $95 \% \mathrm{Cl}$

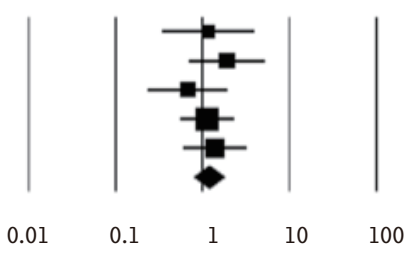

Favors EVT alone Favours EVT with IVT

\section{Odds ratio and $95 \% \mathrm{Cl}$}

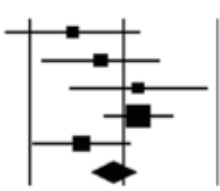

$\begin{array}{lllll}0.01 & 0.1 & 1 & 10 & 100\end{array}$

Favors EVT with IVT Favours EVT alone

\section{Odds ratio and $95 \% \mathrm{Cl}$}

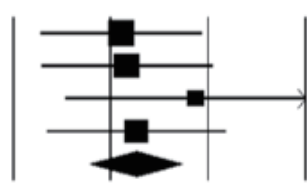

$\begin{array}{lllll}0.01 & 0.1 & 1 & 10 & 100\end{array}$

Favours EVT with IVT Favors EVT alone

Fig. 2. Comparison of treatment outcomes between endovascular treatment (EVT) with intravenous thrombolysis (IVT) and EVT alone in terms of successful recanalization rate (A), good clinical outcomes at three months (B), mortality (C), and symptomatic intracranial hemorrhage (D). Cl : confidence interval. 
Kendall's tau was 0 with two-tailed $p$ value of 1.00 . Accordingly, there was no evidence of publication bias in these comparisons. Funnel plot asymmetry was not noted on comparisons either (data now shown).

\section{DISCUSSION}

Whether prior IVT attributes to clinical improvement and facilitates EVT procedures remains unclear ${ }^{6}$. According to Dávalos et al. ${ }^{6}$, EVT with IVT has better outcome than EVT alone group using Solitaire FR (ev3-Covidien, Irvine, CA, USA) $(66 \%$ vs. $42 \%, p<0.01)$. However, there is no significant difference in successful recanalization rate ( $86.5 \%$ vs. $83.6 \%)$ or S-ICH (3.0\% vs. $4.5 \%)$. Guedin et al. ${ }^{10)}$ have shown that EVT with IVT has higher complete recanalization rate $(85.7 \%$ vs. $55.0 \%)$ and better clinical outcomes (67.9\% vs. $52.5 \%)$ than EVT alone with significant decrease in time from groin puncture to maximal recanalization $(p=0.043)$. Maier et al. ${ }^{17)}$ have also disclosed that EVT with IVT tends to have better clinical outcome ( $47.3 \%$ vs. $25 \%, p=0.06)$ and successful recanalization $(72.8 \%$ vs. $53.6 \%, p=0.099)$ than EVT alone without significant difference in the time from groin to recanalization (mean time, 54 minutes vs. 50 minutes; $p=0.657$ ). On the contrary, Sallustio et al. ${ }^{20)}$ have shown that EVT alone (40\%) and EVT with IVT (43\%) have similar good outcome at three months after the procedure. Weber et al. ${ }^{21)}$ have also demonstrated that successful recanalization rate $(73.8 \%$ in EVT with IVT vs. $73.1 \%$ in EVT alone; $p=0.95$ ), good outcome (35.2\% in EVT with IVT vs. $40.0 \%$ in EVT alone; $p=0.44$ ), and the number of passes of thrombectomy devices (median, 1 in EVT with IVT vs. 2 in EVT alone; $p=0.90$ ) are not significantly different between the two groups. Our meta-analysis also revealed that successful recanalization, mortality and S-ICH did not differ significantly according to prior IVT. Good clinical outcome at three months was observed more in patients treated with EVT with IVT than that in EVT alone. However, the difference between the two was not statistically significant. Selection bias due to treatment indication of EVT can be a limitation when interpreting results. Most EVT are performed for patients who are not indicated for IVT ${ }^{20)}$. In particular, different indication criteria of ischemic symptom onset time (up to 4.5 hours in EVT with IVT vs. up to eight hours in EVT alone ${ }^{15)}$ ) could attribute to clinical outcomes.
After literature review, four studies ${ }^{3,13,19,211}$ compared treatment outcomes between EVT with IVT and EVT alone group for patients within 4.5 hours of ischemic symptoms. Rai et al. ${ }^{19)}$ have reported that differences in recanalization rate $(81.6 \%$ in EVT with IVT vs. $81 \%$ in EVT alone, $p=0.93$ ), good outcome (58\% in EVT with IVT vs. $54 \%$ in EVT alone, $p=0.75$ ) and mortality rate (10.5\% in EVT with IVT vs. $19.2 \%$ in EVT alone, $p=0.33$ ) are not statistically significant. Kass-Hout et al. ${ }^{13)}$ have also reported that there is no significant difference in successful recanalization rate $83.3 \%$ in EVT with IVT vs. 79.0\% in EVT alone, $p=0.59$ ), good outcome (37.5\% in EVT with IVT vs. $34.5 \%$ in EVT alone, $p=0.64)$, mortality $(19.0 \%$ in EVT with IVT vs. $29.0 \%$ in EVT alone, $p=0.56$ ), or S-ICH (11.9\% in EVT with IVT vs. 9.7\% in EVT alone, $p=0.75$ ), although time to recanalization appears to be shorter in EVT with IVT (mean, 65.7 minutes) compared to that in EVT alone (mean, 74.6 minutes) $(p=0.29)$. Although the EVT alone group included patients within therapeutic time window of 4.5 hours, EVT was also performed for patients who had contraindication to IVT such as recent stroke, hemorrhage, anti-coagulation, and metastatic cancer etc ${ }^{13,19)}$. In addition, EVT was performed after failure of IVT ${ }^{13)}$. Accordingly, accurate effect of IVT on EVT outcome cannot be obtained. Broeg-Morvay et al. ${ }^{3)}$ have compared treatment outcomes between EVT with IVT and EVT alone for patients qualified for IVT. Time from symptom onset to endovascular thrombolysis was significantly shortened in direct EVT alone compared to that in EVT with IVT group (mean, 3.81 hours vs. 4.37 hours; $p=0.01$ ). After propensity score matching with multivariate analysis, EVT alone groups had significantly lower mortality rate compared to EVT with IVT (20\% in EVT alone vs. $47.5 \%$ in EVT with IVT). However, successful recanalization rate, S-ICH, and good clinical outcome did not differ significantly between the two groups. Weber et al. ${ }^{21)}$ have reported that EVT alone group had higher good outcome rate (48.6\%) for patients eligible for IVT than the EVT with IVT group (35.2\%). Procedural complications such as emboli in further vessel territories, arterial dissection and SAH did not differ significantly between the two groups. Our meta-analysis revealed that EVT with IVT and EVT alone groups did not differ significantly in successful recanalization (OR $0.797, p=0.435$ ), good clinical outcome (OR $0.773, p=0.275)$, mortality (OR 1.185, $p=0.534$ ), or S-ICH (OR 1.973, $p=0.303$ ). Accordingly, EVT alone seems to be as effective as EVT with IVT for acute anterior circula- 
tion stroke within therapeutic time window.

Clot location could be a confounding factor to assess treatment outcome. Kaesmacher and Kleine ${ }^{12)}$ have examined the effect of IVT on EVT outcome according to clot location (proximal vs. distal middle cerebral artery [MCA]). In their study, beneficial effect of EVT with IVT was evident only in distal MCA occlusion. IVT significantly increased complete recanalization (OR 4.5, $p=0.006)$ for distal MCA, but not for proximal MCA occlusion (OR 1.3, $p=0.619$ ). It also significantly improved neurological outcome (OR 2.4, $p=0.047$ ). First-pass rate in EVT with IVT appears to be higher in patients with distal MCA (OR 2.4, $p=0.082)$ than that in patients with proximal MCA occlusion (OR 1.6, $p=0.375$ ). They concluded that IVT promoted thrombectomy effect on distal MCA occlusion with small clinical benefit as overall net effect. Accordingly, further studies are needed to determine the effect of EVT with IVT according to clot location.

This study has some limitations. First, the present study could not provide direct evidence for primary EVT as the first therapeutic option for all ischemic stroke patients eligible for IVT because some patients (approximately 46\%) have recovered well with $\mathrm{IVT}^{16)}$. In addition, four out of five enrolled studies defined EVT alone group as the patients who had contraindication to IVT. Second, inherent selection bias originating from clinical characteristics such as onset to door time, advanced age, anticoagulation status, and comorbid diseases as well as retrospective nature of the enrolled studies might have affected results. In clinical circumstances, there might be a delay in treatment of EVT with IVT compared to EVT alone, particular when large artery occlusion was present. Recently, stent retrieval thrombectomy ${ }^{4)}$ and direct aspiration of thrombus using high-trackable large-bore aspiration catheters $^{14)}$ have shown efficacy for larger artery occlusion with low complication rates. Accordingly, further randomized prospective controlled studies are needed to compare treatment efficacy between primary EVT and EVT with IVT considering occlusion site, particularly for patients who are highly resistant to IVT to obtain more specific indications.

\section{CONCLUSION}

Our meta-analysis showed that EVT with IVT and EVT alone could be comparable for the treatment of acute anterior circulation stroke. Interventionist would consider EVT as the first line therapy for acute ischemic stroke patients who were ineligible for IVT without delay. Further studies to find specific beneficiary group for EVT alone should be performed.

\section{CONFLICTS OF INTEREST}

No potential conflict of interest relevant to this article was reported.

\section{INFORMED CONSENT}

This type of study does not require informed consent.

\section{- Acknowledgements}

This research was supported by a grant (PJ01121401) from BioGreen 21 of the Rural Development Administration, and partly by National Research Foundation of Korea grant funded by the Ministry of Science, Information and Communication Technologies and Future Planning of the Korea Government (No. 2017M3A9E8033223).

\section{References}

1. Almekhlafi MA, Menon BK, Freiheit EA, Demchuk AM, Goyal M : A meta-analysis of observational intra-arterial stroke therapy studies using the Merci device, penumbra system, and retrievable stents. AJNR Am J Neuroradiol 34 : 140-145, 2013

2. Begg $C B$, Mazumdar $M$ : Operating characteristics of a rank correlation test for publication bias. Biometrics 50 : 1088-1101, 1994

3. Broeg-Morvay A, Mordasini P, Bernasconi C, Buhlmann M, Pult F, Arnold $M$, et al. : Direct mechanical intervention versus combined intravenous and mechanical intervention in large artery anterior circulation stroke: a matched-pairs analysis. Stroke 47 : 1037-1044, 2016

4. Broussalis E, Trinka E, Hitzl W, Wallner A, Chroust V, Killer-Oberpfalzer $M$ : Comparison of stent-retriever devices versus the Merci retriever for endovascular treatment of acute stroke. AJNR Am J Neuroradiol 34 : 366-372, 2013

5. Bush CK, Kurimella D, Cross LJ, Conner KR, Martin-Schild S, He J, et al. : Endovascular treatment with stent-retriever devices for acute ischemic stroke: a meta-analysis of randomized controlled trials. Plos One 11 : e0147287, 2016

6. Dávalos A, Pereira VM, Chapot R, Bonafé A, Andersson T, Gralla J, et al. : Retrospective multicenter study of Solitaire FR for revascularization in 
the treatment of acute ischemic stroke. Stroke 43 : 2699-2705, 2012

7. González RG, Furie KL, Goldmacher GV, Smith WS, Kamalian S, Payabvash S, et al. : Good outcome rate of $35 \%$ in IV-tPA-treated patients with computed tomography angiography confirmed severe anterior circulation occlusive stroke. Stroke 44 : 3109-3113, 2013

8. Goyal M, Menon BK, van Zwam WH, Dippel DW, Mitchell PJ, Demchuk AM, et al. : Endovascular thrombectomy after large-vessel ischaemic stroke: a meta-analysis of individual patient data from five randomised trials. Lancet 387 : 1723-1731, 2016

9. Grech R, Pullicino R, Thornton J, Downer J : An efficacy and safety comparison between different stentriever designs in acute ischaemic stroke: a systematic review and meta-analysis. Clin Radiol 71 : 48-57, 2016

10. Guedin P, Larcher A, Decroix JP, Labreuche J, Dreyfus JF, Evrard S, et al. : Prior IV thrombolysis facilitates mechanical thrombectomy in acute ischemic stroke. J Stroke Cerebrovasc Dis 24 : 952-957, 2015

11. Jeon JP, Kim JE : A recent update of clinical and research topics concerning adult moyamoya disease. J Korean Neurosurg Soc 59 : 537-543, 2016

12. Kaesmacher J, Kleine JF : Bridging therapy with i. v. rtPA in MCA occlusion prior to endovascular thrombectomy: a double-edged sword? Clin Neuroradiol $28: 81-89,2018$

13. Kass-Hout T, Kass-Hout O, Mokin M, Thesier DM, Yashar P, Orion D, et al. : Is bridging with intravenous thrombolysis of any benefit in endovascular therapy for acute ischemic stroke? World Neurosurg 82 : e453e458, 2014

14. Lapergue B, Blanc R, Guedin P, Decroix JP, Labreuche J, Preda C, et al. : $A$ direct aspiration, first pass technique (ADAPT) versus stent retrievers for acute stroke therapy: an observational comparative study. AJNR Am J Neuroradiol 37 : 1860-1865, 2016

15. Leker RR, Pikis S, Gomori JM, Cohen JE : Is bridging necessary? A pilot study of bridging versus primary stentriever-based endovascular reperfusion in large anterior circulation strokes. J Stroke Cerebrovasc Dis 24 : 1163-1167, 2015

16. $\mathrm{Ma} \mathrm{QF}$, Chu $\mathrm{CB}$, Song $\mathrm{HQ}$ : Intravenous versus intra-arterial thrombolysis in ischemic stroke: a systematic review and meta-analysis. PloS One 10 : e0116120, 2015

17. Maier IL, Behme D, Schnieder M, Tsogkas I, Schregel K, Kleinknecht A, et al. : Bridging-therapy with intravenous recombinant tissue plasminogen activator improves functional outcome in patients with endovascular treatment in acute stroke. J Neurol Sci 372 : 300-304, 2017

18. Qian C, Yu X, Li J, Chen J, Wang L, Chen G : The efficacy of surgical treatment for the secondary prevention of stroke in symptomatic moyamoya disease: a meta-analysis. Medicine (Baltimore) 94 : e2218, 2015

19. Rai AT, Boo S, Buseman C, Adcock AK, Tarabishy AR, Miller MM, et al. : Intravenous thrombolysis before endovascular therapy for large vessel strokes can lead to significantly higher hospital costs without improving outcomes. J Neurointerv Surg 10 : 17-21, 2018

20. Sallustio F, Koch G, Di Legge S, Rossi C, Rizzato B, Napolitano S, et al. : Intra-arterial thrombectomy versus standard intravenous thrombolysis in patients with anterior circulation stroke caused by intracranial arterial occlusions: a single-center experience. J Stroke Cerebrovasc Dis 22 : e323-e331, 2013

21. Weber $R$, Nordmeyer $H$, Hadisurya J, Heddier M, Stauder M, Stracke $P$, et al. : Comparison of outcome and interventional complication rate in patients with acute stroke treated with mechanical thrombectomy with and without bridging thrombolysis. J Neurointerv Surg 9 : 229-233, 2017 